\title{
MAP kinases and mTOR mediate insulin-induced phosphorylation of Insulin Receptor Substrate-1 on serine residues 307, 612 and 632
}

\author{
P. Gual, T. Grémeaux, T. Gonzalez, Y. Le Marchand-Brustel, J.-F. Tanti \\ INSERM U568 and IFR50, Faculté de Médecine, Nice, France
}

\begin{abstract}
Aim/hypothesis. Insulin-induced IRS-1 serine phosphorylation could be physiologically important to regulate insulin action. In a hyperinsulinaemic state such as obesity or Type 2 diabetes, this phosphorylation could be modified and exacerbate insulin resistance. We aimed at identifying serine residues in IRS-1 phosphorylated in response to insulin stimulation and at determining the involved kinases.

Methods. 3T3-L1 adipocytes, muscle and adipose tissue of mice were subjected to Western Blot analysis with phosphospecific antibodies to identify phosphorylation sites in IRS-1 following insulin treatment. Pharmacological inhibitors were used to determine the serine kinases involved in this phosphorylation.

Results. In 3T3-L1 adipocytes, insulin promoted the phosphorylation of serine 307, 612 and 632 with Serine $^{612 / 632}$ more rapidly phosphorylated than Serine ${ }^{307}$. Insulin-induced phosphorylation of Serine ${ }^{307}$ was dependent on the activation of a PI 3-kinase/mTOR path-
\end{abstract}

way. The phosphorylation of Serine ${ }^{612 / 632}$ required the activation of the MAP kinase pathway following shortterm insulin stimulation and activation of the PI 3-kinase/mTOR pathway following prolonged insulin stimulation. Phosphorylation of Serine ${ }^{307}$ and Serine ${ }^{632}$ occurred in vivo in skeletal muscle and white adipose tissue of mice injected with insulin and was dependent on the activation of mTOR. Moreover, inhibition of mTOR led to a persistent PI 3-kinase activation by insulin.

Conclusion/Interpretation. Insulin-induced IRS-1 serine phosphorylation is a complex process involving different sites and kinases. This complexity could be physiologically important to accurately regulate insulin signalling. Abnormal phosphorylation of these serine residues in hyperinsulinaemic state could participate in the down-regulation of insulin signalling. [Diabetologia (2003) 46:1532-1542]

Keywords IRS-1, PI 3-kinase, insulin resistance, diabetes, serine phosphorylation, muscles, adipose tissue, 3T3-L1 adipocytes, rapamycin.
Received: 26 February 2003 / Revised: 30 June 2003

Published online: 25 October 2003

(C) Springer-Verlag 2003

Corresponding author: Y. Le Marchand-Brustel, INSERM U568 and IFR50, Faculté de Médecine, Avenue de Valombrose, 06107 Nice Cedex 02, France

E-mail: lemarcha@unice.fr

Abbreviations: PI 3-kinase, phosphatidylinositol 3-kinase; mTOR, mammalian target of rapamycin; APS, adaptor with a $\mathrm{PH}$ and SH2 domains; Shc, Src Homology Collagen; SH2, Src Homology 2; PTB, phosphotyrosine binding; MAP, mitogenactivated protein; MEK, mitogen-activated protein kinase kinase; $\mathrm{PKB}$, protein kinase $\mathrm{B}$; PDGF, platelet derived growth factor; JNK, c-Jun NH2 terminal kinase; PMA, phorbol myristate acetate; PIP3, phosphatidylinositol 3,4,5 triphosphates.
Insulin is the primary hormone involved in glucose homeostasis, and impairment of both insulin action and secretion leads to development of Type 2 diabetes $[1,2]$. The earliest abnormality observed in insulin resistance is a decrease in insulin-induced glucose uptake in skeletal muscle and adipose tissue and a reduced ability of the hormone to suppress glucose production by the liver $[1,2]$. At the early stage of the pathology, pancreatic beta cells can compensate for peripheral insulin resistance by increasing insulin secretion $[1,3]$. However, the persistence of hyperinsulinaemia might impair insulin action due to the activation of counter regulatory mechanisms involved in the desensitisation of insulin effect on glucose uptake. It 
could exacerbate the demand for insulin and promote the development of overt diabetes [1,4].

Insulin binds to its receptor and increases its tyrosine kinase activity leading to the phosphorylation of several cellular substrates including Shc, APS, Cbl and the IRS proteins [4]. There are four different isoforms of IRS proteins identified which lack intrinsic catalytic activity but which, following their tyrosine phosphorylation, bind and activate various proteins containing SH2 domains. Among them, phosphatidylinositol 3-kinase (PI 3-kinase) is an essential component of the insulin signalling system leading to the stimulation of glucose uptake [4]. Recent works, based on the use of transgenic animals, suggest that IRS-1 mediates the insulin effect on glucose uptake in muscles and adipose tissue [5]. Defects in IRS-1 tyrosine phosphorylation have been reported in target tissues of insulin action from insulin-resistant subjects [6]. Moreover, low amounts of IRS-1 and of its tyrosine phosphorylation have been reported in $30 \%$ of subjects at high risk for Type 2 diabetes such as firstdegree relatives of Type 2 diabetic and obese subjects [6] or in patients with clinical features of insulin-resistant syndrome [7]. Thus, the decrease in IRS-1 content and tyrosine phosphorylation could be considered as a marker of insulin-resistant states such as obesity and Type 2 diabetes. The molecular mechanisms involved in the decrease in IRS-1 tyrosine phosphorylation in the insulin-resistant state are not completely identified. However, a general agreement about a role of the serine/threonine phosphorylation of IRS-1 is emerging [2]. Indeed, okadaic acid [8], PMA [9, 10], PDGF [11] and hyperosmotic stress [12] increase the serine/threonine phosphorylation of IRS-1 and reduce the subsequent insulin response. Moreover, free fatty acids and proinflammatory cytokines such as TNF $\boldsymbol{\alpha}$ [13] produced during obesity and associated with insulin resistance stimulate the serine phosphorylation of IRS-1. Although Ser/Thr phosphorylation of IRS-1 was often linked to a down-regulation of insulin signalling, it could also positively modulate insulin action [14, 15]. Insulin itself induces the serine phosphorylation of IRS-1 that could be physiologically important to regulate insulin signalling. In hyperinsulinaemic states such as obesity or Type 2 diabetes, this Ser/Thr phosphorylation could be disturbed and exacerbate insulin resistance.

IRS-1 contains nearly 100 potential serine phosphorylation sites and can be phosphorylated by many kinases in vivo or in vitro [16]. Thus, the identification of the serine phosphorylation sites and of the kinases that are involved in insulin resistance is difficult. Recently, the use of a phosphospecific antibody against $\mathrm{Ser}^{307}$ in IRS-1 demonstrated that TNF $\alpha$ [17] and free fatty acids [18] stimulate the phosphorylation of this site. Mutation of this serine residue prevents the inhibitory effect of TNF $\alpha$ on insulin-induced IRS1 tyrosine phosphorylation [19]. Moreover, it has been shown that c-Jun NH2-terminal kinase (JNK) phosphorylates the $\mathrm{Ser}^{307}$ resulting in an inhibition of the interaction between the PTB domain of IRS-1 and the activated insulin receptor [20].

In this study, we aimed at identifying serine residues phosphorylated in response to insulin stimulation and at determining the signalling pathways required for this process. We used phosphospecific polyclonal antibodies that specifically recognise phosphorylated Ser ${ }^{307}$, Ser612 or Ser632. Ser612 and Ser632 which are phosphorylated following TPA $[9,10]$ and TNF $\alpha[21]$ treatment respectively, are located at the +4 position of tyrosine residues in YMXM motif involved in the binding of PI 3-kinase. Phosphorylation of these tyrosine residues ( $\mathrm{Tyr}^{608}$ and $\mathrm{Tyr}^{628}$ ) is crucial for insulin induced PI 3-kinase activation and glucose uptake [22]. Using these antibodies, we show that insulin induces the phosphorylation of these serine residues both in 3T3-L1 adipocytes and in vivo in skeletal muscle and adipose tissue suggesting an important physiological role of these phosphorylations. Moreover, we provide strong evidence that MAP kinases and mTOR can be involved in the phosphorylation of these sites.

\section{Materials and methods}

Materials. Dulbecco's modified Eagle medium (DMEM), fetal calf serum and calf serum were obtained from Invitrogen SARL (Cergy Pontoise, France). PD-98059 and Rapamycin were from Calbiochem (La Jolla, Calif., USA). Wortmaninn was purchased from Sigma (St. Louis, Mo., USA). PVDF membranes were purchased from Millipore (Bedford, Mass., USA). BCA reagent was obtained from Pierce Biotechnology (Rockford, Ill., USA). Protease inhibitor cocktails were obtained from Roche Diagnostics (Mannheim, Germany). All other chemical reagents were purchased from Sigma (St Louis, Mo., USA). Horseradish peroxydase-conjugated secondary antibodies were obtained from Jackson Immunoresearch Laboratories (West Grove, Pa., USA). Enhanced chemiluminescence reagent was purchased from PerkinElmer Life Sciences (Boston, Mass., USA).

Antibodies. Polyclonal anti-IRS-1 antibody and anti-mTOR antibody (mTAb1) were purchased from UBI (Charlottesville, Va., USA). Polyclonal anti-phospho IRS-1-Ser ${ }^{612}$ antibody $\left(\alpha \mathrm{pS}^{612}\right)$ and anti-phospho-p70 S6 kinase (Thr389) were purchased from Cell Signalling (Cell Signalling Technology, Mass., USA). Polyclonal anti-phospho-Ser ${ }^{307}$ antibody $\left(\alpha \mathrm{pS}^{307}\right)$ was raised against a synthetic peptide (ESIT$\mathrm{ATpS}^{307}$ PASMVGGK) flanking Ser $^{307}$ in IRS-1 (Eurogentec, Seraing, Belgium) as previously described [23]. Polyclonal anti-phospho-Ser ${ }^{632}$ antibody $\left(\alpha \mathrm{pS}^{632}\right)$ was raised against the synthetic peptide (GDYMPMpS ${ }^{632}$ PKSVSAP) flanking Ser632 in IRS-1 (Eurogentec, Seraing, Belgium). Both sequences were conserved among mouse, rat and human IRS-1.

Cells culture. 3T3-L1 fibroblasts were grown in 35 or $100 \mathrm{~mm}$ dishes in DMEM, $25 \mathrm{mmol} / \mathrm{l}$ glucose, $10 \%$ calf serum, $50 \mathrm{IU} / \mathrm{ml}$ of penicillin and $50 \mathrm{IU} / \mathrm{ml}$ of streptomycin and induced to differentiate in adipocytes [11]. Briefly, 2 days after confluence, medium was changed for DMEM, $25 \mathrm{mmol} / \mathrm{l} \mathrm{glu-}$ 
cose, $10 \%$ fetal calf serum (FCS), $50 \mathrm{IU} / \mathrm{ml}$ of penicillin and $50 \mu \mathrm{g} / \mathrm{ml}$ of streptomycin supplemented with isobutylmethylxanthine $(0.25 \mathrm{mmol} / \mathrm{l})$, dexamethasone $(0.25 \mu \mathrm{mol} / \mathrm{l})$ and insulin $(5 \mu \mathrm{g} / \mathrm{ml})$. The medium was removed after 2 days and replaced with DMEM, $25 \mathrm{mmol} / 1$ glucose, 10\% FCS, $50 \mu \mathrm{mol} / \mathrm{l}$ of penicillin and $50 \mu \mathrm{g} / \mathrm{ml}$ of streptomycin supplemented with insulin for two other days. Then, the cells were fed every 2 days with DMEM, $25 \mathrm{mmol} / 1$ glucose, 10\% FCS, $50 \mathrm{IU} / \mathrm{ml}$ of penicillin and $50 \mu \mathrm{g} / \mathrm{ml}$ of streptomycin. 3T3-L1 adipocytes were used 8-15 days after the beginning of the differentiation protocol. The medium was changed to serum-free DMEM supplemented with $0.5 \%$ (w/v) bovine serum albumin, $16 \mathrm{~h}$ before each experiment.

L6 myoblast cells were grown in MEM supplemented with $10 \% \mathrm{FCS}, 50 \mathrm{IU} / \mathrm{ml}$ of penicillin and $50 \mu \mathrm{g} / \mathrm{ml}$ of streptomycin.

Plasmids and transient transfection. The rat IRS-1 cDNA subcloned into pBluescript II KS was obtained from CR Kahn (Joslin Diabetes Center, Boston, Mass., USA). Ser ${ }^{307}$ or Ser ${ }^{632}$ in rat IRS-1 was mutated to alanine (IRS-1 1 S307A or IRS-1S632A) with the QuickChange site-directed mutagenesis kit (Stratagene, La Jolla, Calif., USA). The mutation was verified by DNA sequencing. Wild-type IRS-1, IRS-1(S307A) or IRS1 (S632A) were cloned into the eucaryotic expression vector pCEP-4 under the control of a cytomegalovirus promoter. The plasmid DNAs were obtained using Qiagen purification kit (Qiagen, Courteboeuf, France), and their concentrations were determined by measuring the OD at $260 \mathrm{~nm}$.

L6 myoblast cells were split in $35 \mathrm{~mm}$ dishes $(200000$ cells/dishes) $24 \mathrm{~h}$ before transfection. The cells were transfected with $0.5 \mu \mathrm{g}$ of plasmid coding for wild-type IRS- 1 or mutated IRS-1 per dish (the total amount of plasmid per dish was adjusted to $2 \mu \mathrm{g}$ using empty vector), using Fugene 6 according to the protocol recommended by the manufacturer. The cells were used for experiments $48 \mathrm{~h}$ after transfection.

Immunoprecipitation and immunoblotting. 3T3-L1 adipocytes or L6 myoblast cells were serum-starved overnight in $\mathrm{DMEM} / 0.5 \% \mathrm{BSA}(\mathrm{w} / \mathrm{v})$ and treated without or with insulin $(100 \mathrm{nmol} / \mathrm{l})$ for different periods of time at $37^{\circ} \mathrm{C}$. When present, kinase inhibitors were added $30 \mathrm{~min}$ before insulin stimulation. The cells were washed with ice-cold PBS and then washed with ice-cold buffer $(20 \mathrm{mmol} / \mathrm{l}$ Tris $\mathrm{pH} 7.4$, $150 \mathrm{mmol} / \mathrm{l} \mathrm{NaCl}, 5 \mathrm{mmol} / \mathrm{l}$ EDTA, $150 \mathrm{mmol} / \mathrm{l} \mathrm{NaF}$, and $2 \mathrm{mmol} / \mathrm{l}$ sodium orthovanadate) before solubilization for $30 \mathrm{~min}$ at $4^{\circ} \mathrm{C}$ in lysis buffer $[20 \mathrm{mmol} / 1$ Tris $\mathrm{pH} 7.4$, $150 \mathrm{mmol} / \mathrm{l} \mathrm{NaCl}, 5 \mathrm{mmol} / \mathrm{l}$ EDTA, $150 \mathrm{mmol} / \mathrm{l} \mathrm{NaF}$, $2 \mathrm{mmol} / \mathrm{l}$ sodium orthovanadate, $100 \mathrm{nmol} / \mathrm{l}$ okadaic acid, protease inhibitors, and $1 \%$ Triton X-100 (v/v)]. Following centrifugation at $14000 \mathrm{~g}$ for $10 \mathrm{~min}$ at $4^{\circ} \mathrm{C}$, the supernatant (cell lysates) was incubated for $4 \mathrm{~h}$ at $4^{\circ} \mathrm{C}$ with anti IRS- 1 antibody ( $5 \mu \mathrm{g}$ of antibody/sample) preadsorbed on protein-ASepharose beads. The beads were washed three times with the lysis buffer and boiled for $5 \mathrm{~min}$ in Laemmli buffer. The proteins were separated by SDS-PAGE using a $7.5 \%$ resolving gel. Proteins were transferred to PVDF membrane and the membrane was blocked with saline buffer $(10 \mathrm{mmol} / \mathrm{l}$ Tris $\mathrm{pH} 7.4,140 \mathrm{mmol} / \mathrm{l} \mathrm{NaCl})$ containing 5\% (w/v) non-fat dry milk for $2 \mathrm{~h}$ at room temperature and incubated overnight at $4^{\circ} \mathrm{C}$ with the indicated antibody. Following incubation with horseradish-peroxydase conjugated secondary antibodies, proteins were detected by enhanced chemiluminescence (ECL). Some membranes were subsequently incubated at $55^{\circ} \mathrm{C}$ for $30 \mathrm{~min}$ in stripping buffer $(62 \mathrm{mmol} / 1$ Tris $\mathrm{pH} 6.7$, $100 \mathrm{mmol} / \mathrm{l}$ 2-mercaptoethanol, and 2\% SDS) and reprobed with the indicated antibody.
A
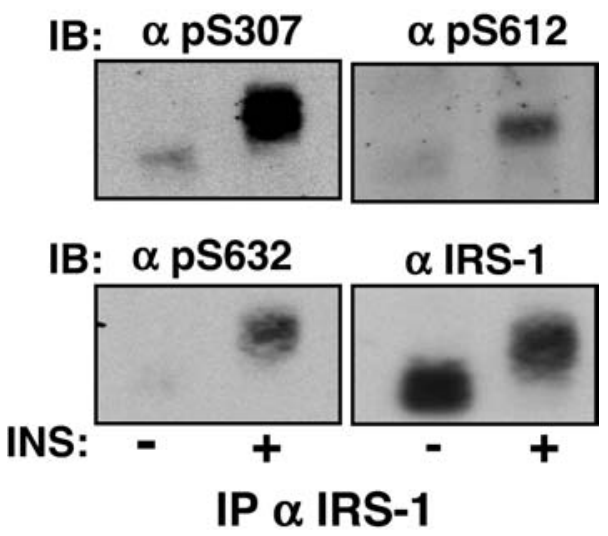

B
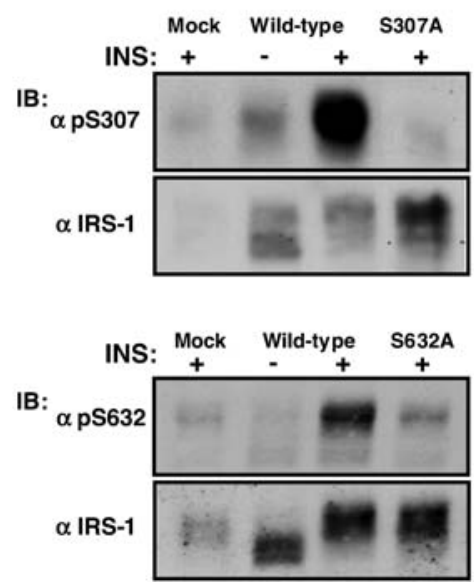

Fig. 1A, B. Insulin induces the phosphorylation of $\mathrm{Ser}^{307}$, Ser ${ }^{612}$ and Ser632 of IRS-1 in 3T3-L1 adipocytes. (A) After serum starvation, 3T3-L1 adipocytes were incubated without or with insulin $(100 \mathrm{nmol} / \mathrm{l})$ for $1 \mathrm{~h}$. Cell lysates were immunoprecipitated with anti-IRS-1 antibody. Proteins were resolved by SDS-PAGE and immunoblotted with phosphospecific antibodies $(\alpha p S)$ against $\operatorname{Ser}^{307}$, Ser ${ }^{612}$ or $\operatorname{Ser}^{632}$. The amount of IRS-1 in the immunoprecipitation was detected by probing the membranes with anti-IRS-1 antibody. Representative immunoblots of three different experiments are shown. (B) L6 myoblasts were transfected with empty vector (mock), pCep IRS$1^{\text {wt }}$ (wild-type), pCep IRS-1 (S307A) or (S632A). Cells were incubated without or with insulin $(1 \mu \mathrm{mol} / \mathrm{l})$ for $1 \mathrm{~h}$. IRS-1 was immunoprecipitated from cell lysate and immunoblotted with apS307 or $\alpha$ pS632 antibodies. Membrane was then stripped and probed with anti-IRS-1 antibody

Animals. Swiss albino male mice (35-40 g) were purchased from Charles River Laboratories (St. Aubin les Elbeuf, France) and housed at the animal facility at the Faculty of Medicine (Nice, France). Mice were maintained on a 12 h:12 h light:dark cycle and were provided free access to water and standard rodent chow. Animals were fasted for $6 \mathrm{~h}$ before the beginning of the experiment. Mice were anaesthetised with pentobarbitone sodium and intraperitoneally injected in the tail vein with insulin ( $1 \mathrm{unit} / \mathrm{kg}$ ). When rapamycin was used, it was injected intraperitoneally $(1 \mu \mathrm{g} / \mathrm{g}) 5 \mathrm{~min}$ before insulin injection. Then 20 min after insulin treatment, the mice were killed by cervical dislocation, and soleus muscles or epididymal fat pads were re- 


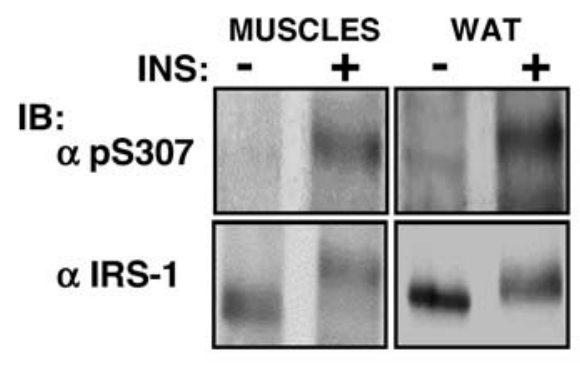

IP: $\alpha$ IRS-1

Fig. 2. Insulin treatment promotes IRS-1 phosphorylation on both $\operatorname{Ser}^{307}$ and Ser632 in skeletal muscle and white adipose tissue. Saline solution or insulin $(1 \mathrm{U} / \mathrm{kg})$ was injected intravenously in anaesthetised mice. 20 min later soleus muscles or epididymal fat pads (WAT) were isolated and homogenised. IRS-1 was immunoprecipitated and immunoblotted with $\alpha \mathrm{pS}^{307}$ or $\alpha \mathrm{pS}^{632}$ antibodies. The amount of IRS-1 in the immunoprecipitation was quantified by immunoblotting with anti-IRS-1 antibody. Typical autoradiographs representative of four different experiments are shown

moved and freeze-clamped in liquid nitrogen. Principles of laboratory animal care were followed and the Ethical Committee of the Faculty of Medicine approved the animal experiments.

Immunopurification of IRS-1 from soleus muscle and adipose tissue of mice. Soleus muscle or adipose tissue was homogenised in lysis buffer $(20 \mathrm{mmol} / \mathrm{l}$ Tris $\mathrm{pH} \mathrm{7.4,} 150 \mathrm{mmol} / \mathrm{l} \mathrm{NaCl}$, $5 \mathrm{mmol} / \mathrm{l}$ EDTA, $150 \mathrm{mmol} / \mathrm{l} \mathrm{NaF}, 2 \mathrm{mmol} / 1$ sodium orthovanadate, $100 \mathrm{nmol} / \mathrm{l}$ okadaic acid, protease inhibitors, and $1 \%$ Triton X-100). We used $1 \mathrm{mg}$ of protein for immunoprecipitation with anti IRS-1 antibody as described above except that the immunoprecipitation was carried out overnight at $4^{\circ} \mathrm{C}$. Phosphorylation of IRS-1 on $\mathrm{Ser}^{307}$ or Ser632 was detected with the anti-phospecific antibodies directed against these sites.

Measurement of PI 3-kinase activity in isolated soleus muscles of mice. Soleus muscles were isolated from 8- to 12-week-old male Swiss albino mice. After isolation, muscles were incubated for $15 \mathrm{~min}$ in $1 \mathrm{ml}$ of DMEM/0.5\%BSA (w/v) at $37^{\circ} \mathrm{C}$. Muscles were then incubated with vehicle or with rapamycin $(40 \mathrm{nmol} / \mathrm{l})$ for $30 \mathrm{~min}$ and then stimulated with insulin $(10 \mathrm{nmol} / \mathrm{l})$ for various periods of times. Muscles were briefly sonicated in $1 \mathrm{ml}$ of lysis buffer (20 mmol/l Tris $\mathrm{pH} 7.4,150 \mathrm{mmol} / \mathrm{l} \mathrm{NaCl}, 5 \mathrm{mmol} / \mathrm{l}$ EDTA, $150 \mathrm{mmol} / \mathrm{l} \mathrm{NaF}, 2 \mathrm{mmol} / \mathrm{l}$ sodium orthovanadate, $100 \mathrm{nmol} / \mathrm{l}$ okadaic acid, protease inhibitors, and 1\% NonidetP40). Proteins were solubilised for $1 \mathrm{~h}$ at $4^{\circ} \mathrm{C}$ and IRS- 1 was immunoprecipitated from each sample with anti IRS-1 antibody ( $5 \mu \mathrm{g} / \mathrm{sample}$ ) pre-adsorbed on protein-A-Sepharose beads. Immunoprecipitation was carrried out for $3 \mathrm{~h}$ at $4^{\circ} \mathrm{C}$ and PI 3-kinase activity was measured on immune pellets [24].

Statistical analysis. Statistical analysis was carried out by Student's $t$-test. A $p$ value of less than 0.05 was considered statistically significant.

\section{Results}

Insulin induces the phosphorylation of Serines 307, 612 and 632 of IRS-1 in 3T3-L1 adipocytes. We first tested whether insulin-stimulated phosphorylation of

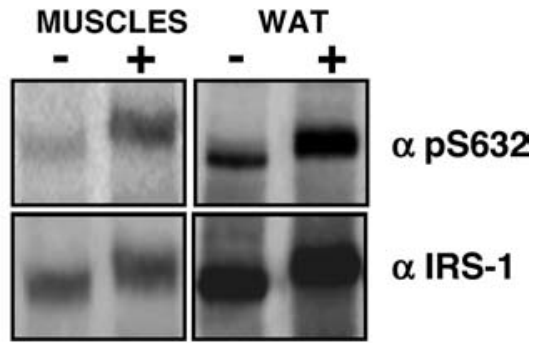

\section{IP: $\alpha$ IRS-1}

IRS- 1 on serines 307, 612 and 632 which are phosphorylated in response to different stimuli such as fatty acids, TNF $\alpha$ or PMA. 3T3-L1 adipocytes were treated without or with $100 \mathrm{nmol} / \mathrm{l}$ insulin for $1 \mathrm{~h}$ and IRS-1 was immunopurified and immunoblotted with phosphospecific antibodies against $\mathrm{Ser}^{307}, \mathrm{Ser}^{612}$ or Ser ${ }^{632}$. In untreated cells, immunoprecipitated IRS-1 did not react with the different phosphospecific antibodies. In contrast, following insulin stimulation, IRS-1 was detected by the three phosphospecific antibodies indicating that insulin stimulated the phosphorylation of the different sites (Fig. 1A). The specificity of the antibodies that we have produced was confirmed by expressing IRS-1 mutated on $\mathrm{Ser}^{307}$ or Ser ${ }^{632}$ in L6 myoblasts. Cells were stimulated with $100 \mathrm{nmol} / \mathrm{l}$ insulin for $1 \mathrm{~h}$ and immunoprecipitated IRS-1 was immunoblotted with $\alpha \mathrm{pS}^{307}$ or $\alpha \mathrm{pS}^{632}$ antibody. Following insulin stimulation of mock transfected cells, endogenous IRS-1 was weakly detected with $\alpha \mathrm{pS}^{307}$ or $\alpha \mathrm{pS}^{632}$ antibodies since L6 myoblasts express low amounts of IRS-1. The $\alpha \mathrm{pS}^{307}$ or $\alpha \mathrm{pS}^{632}$ antibodies detected overexpressed wild-type IRS-1. By contrast, $\alpha \mathrm{pS}^{307}$ and $\alpha \mathrm{pS}^{632}$ antibodies did not recognise over-expressed IRS-1(S307A) and IRS-1(S632A) respectively (Fig. 1B).

Insulin promotes IRS-1 phosphorylation on both Serine 307 and Serine 632 in skeletal muscle and white adipose tissue in vivo. To assess whether the insulininduced phosphorylation of these serine residues was physiologically relevant, we determined if it occurred in whole organism and in particular in muscles and white adipose tissue which play an important role in the regulation of whole-body glucose uptake. Mice were injected with insulin $(1 \mathrm{U} / \mathrm{kg})$ and soleus muscles and epididymal fat pads were isolated $20 \mathrm{~min} \mathrm{la-}$ ter. IRS-1 was immunoprecipitated from the homogenate and immunoblotted with $\alpha \mathrm{pS}^{307}$ or $\alpha \mathrm{pS}^{632}$ antibodies. Both $\operatorname{Ser}^{307}$ and Ser 632 were phosphorylated following insulin treatment (Fig. 2). Phosphorylation of Ser612 was not detected with the commercially available $\alpha \mathrm{pS}^{612}$ antibody.

Insulin induces the phosphorylation of the three serines residues with different time-courses. We examined the kinetics of phosphorylation of the three serine residues in 3T3-L1 adipocytes. Cells were treated with insulin $(100 \mathrm{nmol} / \mathrm{l})$ for various periods of time and immunopurified IRS-1 was immunoblotted with the 

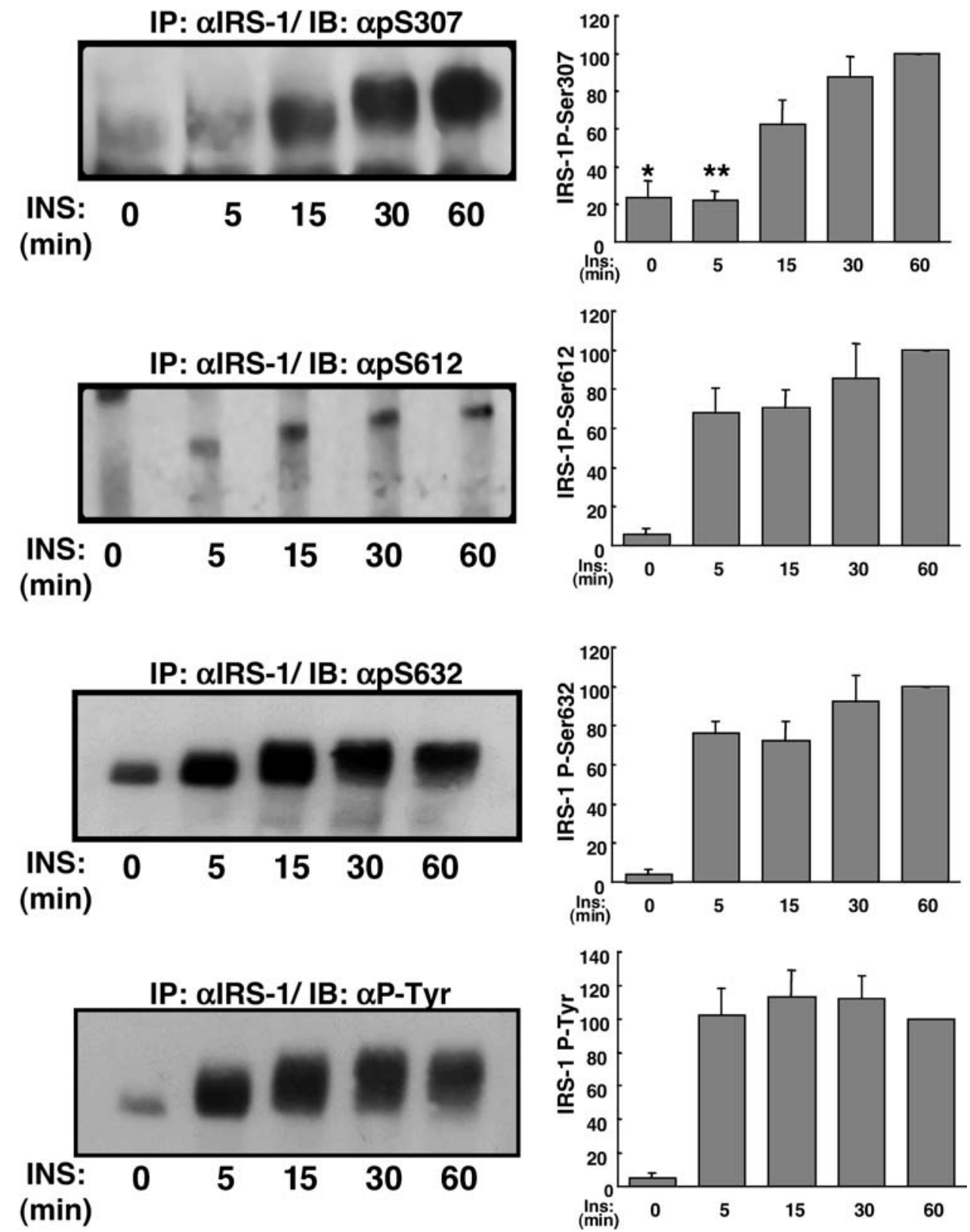

Fig. 3. Insulin induces the phosphorylation of $\operatorname{Ser}^{612 / S e r} 632$ more rapidly than $\mathrm{Ser}^{307}$. After serum starvation, 3T3-L1 adipocytes were stimulated with insulin $(100 \mathrm{nmol} / \mathrm{l})$ for different periods of time. IRS-1 was immunoprecipitated from cell lysate and membranes were separately immunoblotted with the different phosphospecific antibodies $(\alpha p S)$. The amount of IRS-1 in the immunoprecipitation was detected by probing each membrane with anti-IRS-1 antibody. Representative immunoblots are shown in the left panels. Immunoreactive bands were quantified by densitometric scanning analysis and their intensity was normalised for the amount of total IRS-1. The time course of phosphorylation of each serine site was expressed as a percentage of insulin stimulation at $60 \mathrm{~min}$ and results are the means \pm SEM of six to eight independent experiments (right panels). ${ }^{*} \mathrm{Ser}^{307}$ phosphorylation significantly different from Ser ${ }^{612}$ and $\operatorname{Ser}^{632}$ phosphorylation with $p<0.05$; $* * \operatorname{Ser}^{307}$ phosphorylation significantly different from Ser612 and $\operatorname{Ser}^{632}$ phosphorylation with $p<0.01$ different phosphospecific antibodies. Insulin-induced phosphorylation of $\mathrm{Ser}^{307}$ was only detected following 15 min of insulin stimulation while phosphorylation of both $\operatorname{Ser}^{612}$ and $\operatorname{Ser}^{632}$ was more rapid since it reached a maximum following $5 \mathrm{~min}$ of insulin treatment (Fig. 3). The phosphorylation of the three sites was sustained for at least $60 \mathrm{~min}$. The tyrosine phosphorylation of IRS-1 paralleled the phosphorylation of the Ser612 and the Ser632. It should be noted that the small decrease in IRS-1 phosphorylation following 60 min of insulin stimulation (Fig. 3, left panels) was due to the decrease in the amount of IRS-1 due to its rapid degradation. This decrease does not appear when results are corrected for the amount of total IRS-1 proteins (Fig. 3, right panels).

Modulation of IRS-1 phosphorylation on Serines 307, 612 and 632 by the MAP kinase or the PI 3-ki- 

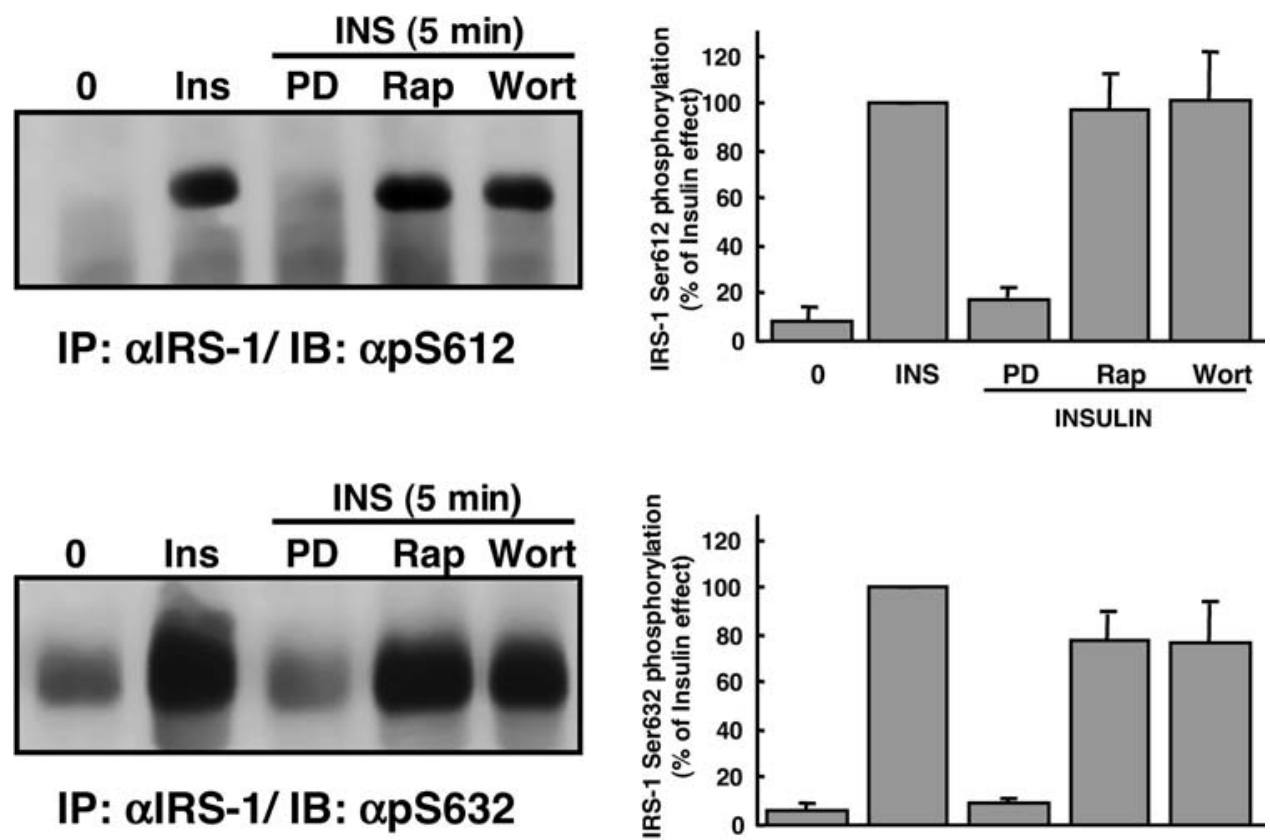

Fig. 4. MAP kinase activation is required for IRS-1 phosphorylation on Ser612 and Ser632 following short-term insulin stimulation. 3T3-L1 adipocytes were pre-treated with vehicle or different pharmacological inhibitors PD98059 (PD, $10 \mu \mathrm{mol} / \mathrm{l})$, rapamycin (Rap, $40 \mathrm{nmol} / \mathrm{l}$ ) or wortmannin (Wort, $100 \mathrm{nmol} / \mathrm{l}$ ) for $30 \mathrm{~min}$ before insulin stimulation $(100 \mathrm{nmol} / \mathrm{l})$ for $5 \mathrm{~min}$. IRS-1 was immunoprecipitated from cell lysate and membranes were separately immunoblotted with $\operatorname{\alpha pS}^{612}$ or $\alpha \mathrm{pS}^{632}$ antibodies. Representative immunoblots are shown (left panel). Results have been normalised for the amount of IRS-1 present in the immunoprecipitation and are the means \pm SEM of three different experiments (right panel)

nase/mTOR pathways. PI 3-kinase, MAP kinase and mTOR pathways have been implicated in the phosphorylation of IRS-1 in response to different stimuli [16]. We thus tested which signalling pathway is required for the phosphorylation of $\mathrm{Ser}^{307}, \mathrm{Ser}^{612}$ and Ser632, using the PI 3-kinase inhibitor wortmannin, the MEK inhibitor PD98059 and the mTOR inhibitor rapamycin. 3T3-L1 adipocytes were incubated with the different pharmacological inhibitors before insulin stimulation for $5 \mathrm{~min}$ or $1 \mathrm{~h}$. Following $5 \mathrm{~min}$ of insulin stimulation, phosphorylation of Ser612 or Ser632 residues was prevented by PD98059 but not by wortmannin or rapamycin (Fig. 4) although it was verified that activation of p70 S6 kinase or PKB was inhibited. This result indicates that MAP kinase activation plays a major role in the phosphorylation of these serine residues after short-term insulin treatment. In contrast, after $1 \mathrm{~h}$ of insulin stimulation, phosphorylation of the three serine residues was inhibited by wortmaninn and rapamycin but not by PD98059 (Fig. 5) although it was verified that MAP kinase activation was inhibited. This result favoured

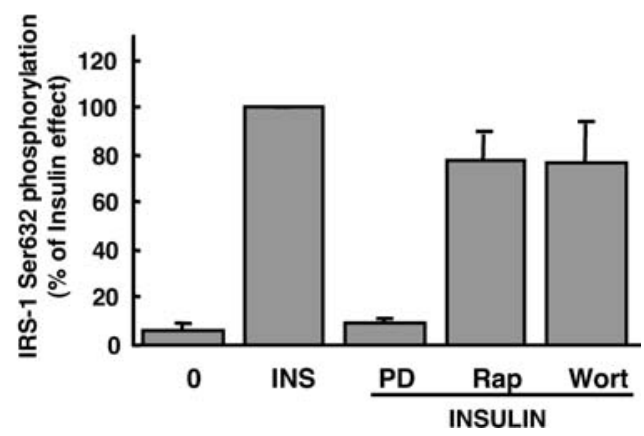

a role of a mTOR dependent signalling pathway downstream of PI 3-kinase in the phosphorylation of these serine residues following prolonged insulin stimulation. Thus, we next investigated whether mTOR and IRS-1 were able to interact. 3T3-L1 adipocytes were treated with insulin for 30 or $60 \mathrm{~min}$, IRS-1 was immunoprecipitated and the presence of mTOR in the immunoprecipitation was assessed by immunoblotting. Endogenous mTOR co-immunoprecipitated with IRS-1 in the absence of insulin treatment and this association was not modified by 30 - or 60-min insulin stimulation (Fig. 6). This interaction is specific since it was not detected with preimmune IgG alone.

mTOR signalling pathway is involved in insulin-induced phosphorylation of IRS-1 on Serine 307 and 632 in muscle and adipose tissue. We then sought to determine whether activation of the mTOR signalling pathway by insulin was required for the phosphorylation of $\mathrm{Ser}^{307}$ and $\mathrm{Ser}^{632}$ in soleus muscle and white adipose tissue in vivo. Mice were treated with rapamycin $(1 \mathrm{mg} / \mathrm{kg})$ before insulin $(1 \mathrm{U} / \mathrm{kg})$ injection. The insulin-induced phosphorylation of both $\mathrm{Ser}^{307}$ and $\operatorname{Ser}^{632}$ was totally inhibited in mice treated with rapamycin compared to control mice both in soleus muscles and adipose tissue (Fig. 7A). As expected, insulin-stimulated p70 S6 kinases activation, detected with a phosphospecific antibody against $\mathrm{Thr}^{389}$, was suppressed (Fig.7B).

Insulin-induced PI 3-kinase activation is sustained in isolated soleus muscle following inhibition of mTOR signalling pathway. To assess the functional consequences of the reduced insulin-stimulated IRS-1 phosphorylation induced by rapamycin treatment, we mea- 

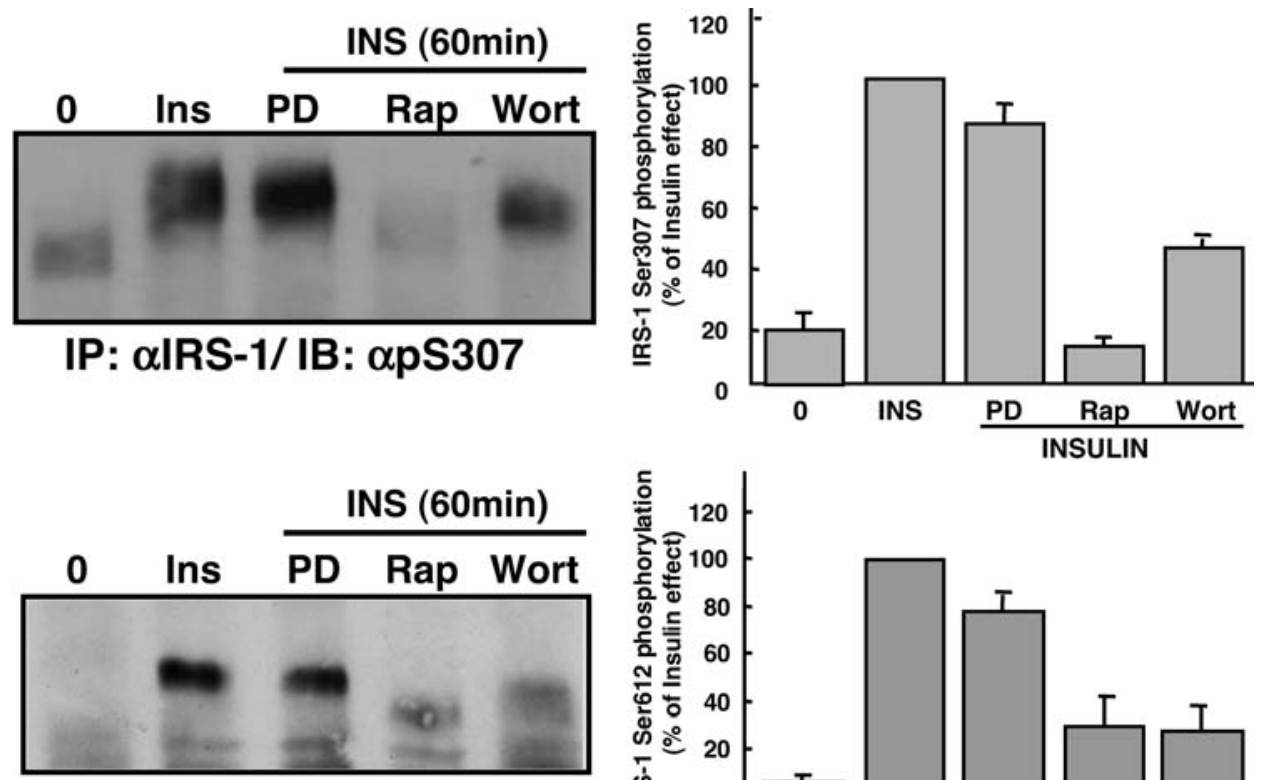

IP: $\alpha$ IRS-1/ IB: $\alpha p S 612$

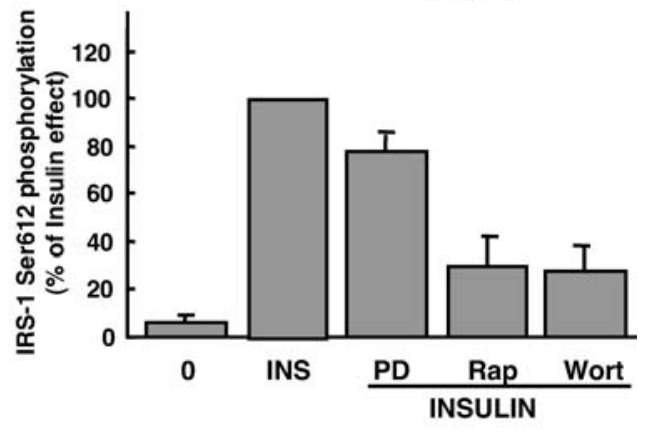

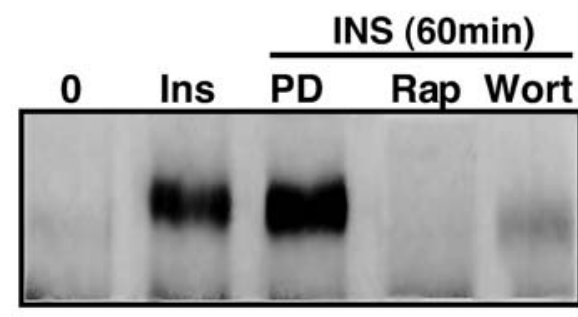

IP: $\alpha$ IRS-1/ IB: $\alpha p S 632$

Fig. 5. IRS-1 phosphorylation on $\operatorname{Ser}^{307}, \operatorname{Ser}^{612}$ and $\operatorname{Ser}^{632}$ is dependent on a PI 3-kinase/mTOR pathway following prolonged insulin stimulation. 3T3-L1 adipocytes were pretreated with vehicle or different pharmacological inhibitors PD98059 (PD, $10 \mu \mathrm{mol} / \mathrm{l})$, rapamycin (Rap, $40 \mathrm{nmol} / \mathrm{l}$ ) or wortmannin (Wort, $100 \mathrm{nmol} / \mathrm{l}$ ) for $30 \mathrm{~min}$ before insulin stimulation (100 nmol/l) for $1 \mathrm{~h}$. IRS-1 was immunoprecipitated from cell lysate and membranes were separately immunoblotted with the $\alpha \mathrm{pS}^{307}, \alpha \mathrm{pS}^{612}$ or $\alpha \mathrm{pS}^{632}$ antibodies. Left panel, Representative immunoblots are shown. Right panel, Results have been normalised for the amount of IRS-1 present in the immunoprecipitation and are the means \pm SEM of three different experiments

sured IRS-1 associated PI 3-kinase activity in soleus muscles treated with or without insulin for various periods of time in the presence or absence of rapamycin. IRS-1-associated PI 3-kinase activity was maximally stimulated after 5 min insulin stimulation and progressively decreased reaching $35 \%$ of maximal activity after 30 min (Fig. 8). Rapamycin treatment did not affect the acute insulin stimulation $(5 \mathrm{~min})$ of PI 3-kinase. However, it dramatically decreased the time-de-

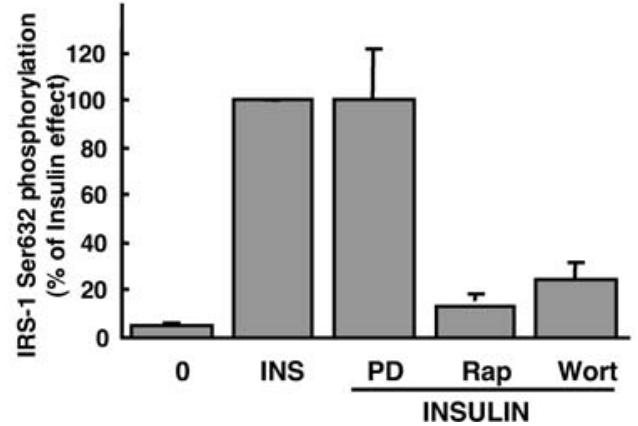

pendent deactivation of PI 3-kinase activity leading to a sustained activation of the enzyme.

\section{Discussion}

Hyperphosphorylation of IRS-1 on Ser/Thr residues has been shown to be associated with insulin-resistant states [16]. Insulin itself can induce the Ser/Thr phosphorylation of IRS-1 which can be a physiological mechanism to regulate insulin signalling. In a hyperinsulinaemic state, this mechanism could be altered and could participate to the reduced insulin response in obesity or Type 2 diabetes. The understanding of the role of these phosphorylations and the identification of the involved kinases are thus a great challenge to understand better the regulation of insulin signalling and its alteration in an insulin-resistant state. In this study, we show that insulin induces the phosphorylation of $\mathrm{Ser}^{307}, \mathrm{Ser}^{612}$ and $\mathrm{Ser}^{632}$ in cells (3T3-L1 adipocytes and L6 myoblasts) and phosphorylation of $\mathrm{Ser}^{307}$ and Ser632 in vivo, in skeletal muscle and adipose tissue. These results suggest that these phos- 


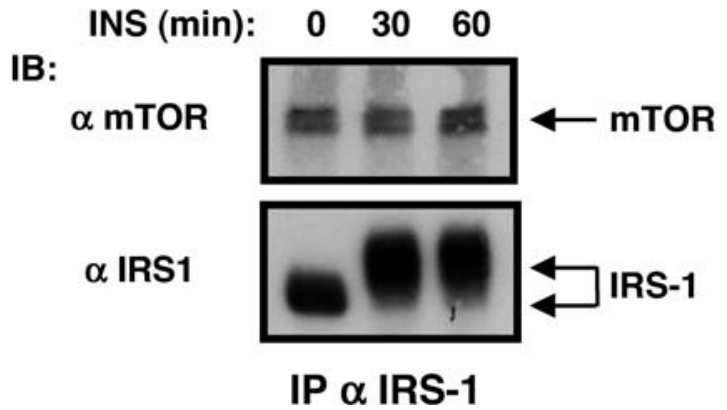

Fig. 6. Association between mTOR and IRS-1 in 3T3-L1 adipocytes. 3T3-L1 adipocytes were stimulated with insulin (100 nmol/l) for 30 or $60 \mathrm{~min}$. IRS-1 was immunoprecipitated from cell lysate and membrane was immunoblotted with mTOR antibody (upper panel). The membrane was then stripped and probed with anti-IRS-1 antibody (lower panel)

A

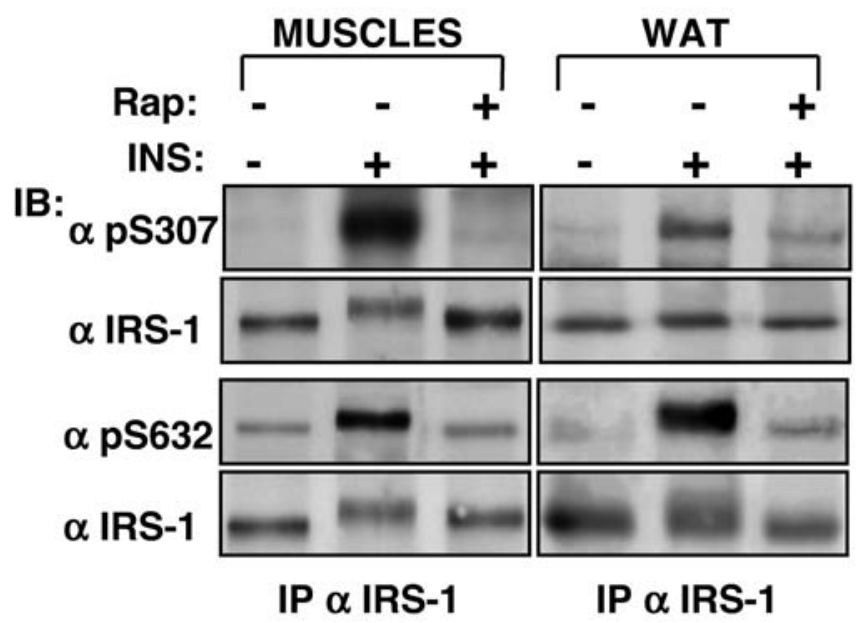

B

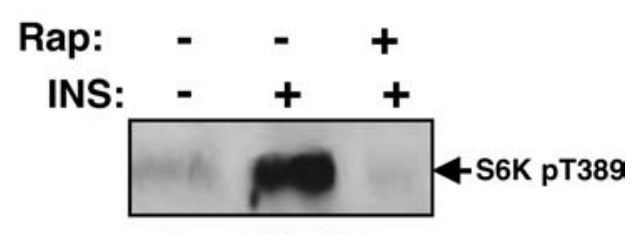

IB: $\alpha$ S6K pT389

Fig. 7A, B. Rapamycin inhibits insulin-induced phosphorylation of both $\mathrm{Ser}^{307}$ and $\mathrm{Ser}^{632}$ in skeletal muscle and adipose tissue in vivo. Anaesthetised mice were injected intraperitoneally with vehicle or rapamycin $(1 \mathrm{mg} / \mathrm{kg})$. Mice were injected, 5 min later, intravenously with saline solution or insulin (1 U/kg). 20 min later, soleus muscles or epididymal fat pads were isolated and homogenised. (A) IRS-1 was immunoprecipitated with a specific antibody and immunoblotted with $\alpha \mathrm{pS}^{307}$ or $\alpha \mathrm{pS}^{632}$ antibodies. The amount of IRS-1 in the immunoprecipitation was quantified by immunoblotting with anti-IRS-1 antibody. Typical autoradiographs representative of three different experiments are shown. (B) Proteins $(50 \mu \mathrm{g})$ from cell lysate obtained from soleus muscle were immunoblotted with a phosphospecific antibody against Thr389 in p70 S6 kinase to detect the activation of the kinase

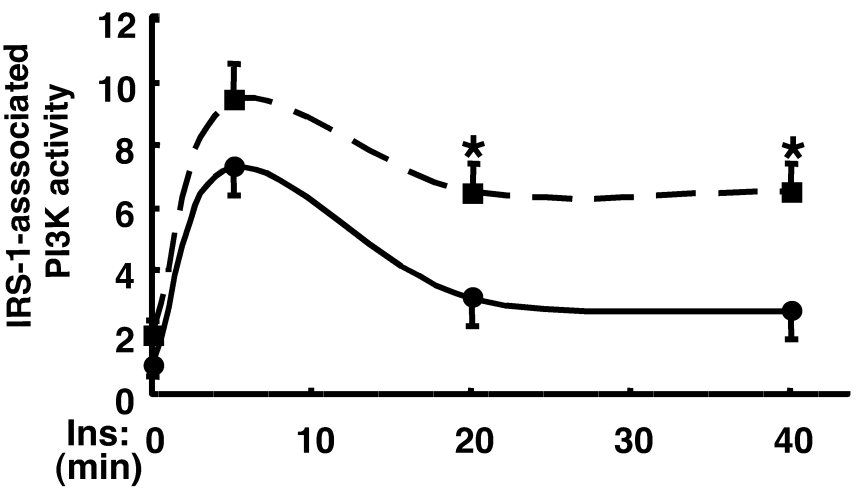

Fig. 8. Rapamycin treatment prolongs the insulin-induced PI 3-kinase activation in isolated soleus muscles. Mouse soleus muscles were isolated and incubated with vehicle (circles) or with rapamycin $(40 \mathrm{nmol} / \mathrm{l})$ (squares) for $70 \mathrm{~min}$. Muscles were stimulated or not with insulin $(10 \mathrm{nmol} / \mathrm{l})$ for the last 5 , 20, 40 min of incubation. Muscles were then lysed, IRS-1 was immunoprecipitated and PI 3-kinase activity was measured in the immune pellet. Results are expressed as fold of the basal activity measured in the absence of insulin and rapamycin and are the means \pm SEM of $6-8$ muscles in each condition. * effect of rapamycin was significant $p<0.01$

phorylations could be physiologically important since they occur in the whole animal. It should be noted that phosphorylation of Ser612 was not detected in vivo. Whether this is due to the lower potency of the antibody compared to the two other phosphospecific antibodies or to the lack of insulin effect on the phosphorylation of this serine residue in the whole animal is still undetermined.

Recent reports have pointed out the importance of the phosphorylation of $\mathrm{Ser}^{307}$ in the negative regulation of insulin signalling [2]. Indeed, several stimuli, including TNF $\alpha$ [17], free fatty acids [18], PMA [25] and osmotic shock [12] increase the phosphorylation of this residue leading to an insulin-resistant state. Ser 307 is located close to the PTB domain of IRS-1 and its phosphorylation could prevent the interaction between IRS-1 and the insulin receptor and hence inhibit the tyrosine phosphorylation of IRS-1 [20]. Moreover, an increase in the phosphorylation of $\mathrm{Ser}^{307}$ in IRS-1 has been reported in high-fat diet obese mice [26], suggesting a role of the phosphorylation of this serine residue in this insulin-resistant state. $\mathrm{Ser}^{307}$ can be phosphorylated by different kinases such as JNK $[19,25,26]$, a MEK-dependent kinase [23], Inhibitor Kappa B kinase (IKK- $\beta$ ) [27] or a kinase activated by the PI 3-kinase [23]. Using pharmacological inhibitors, we found that insulin-induced phosphorylation of Ser ${ }^{307}$ was prevented by the inhibition of PI 3-kinase as previously shown in 3T3-L1 preadipocytes and adipocytes [23]. mTOR is one of the kinases downstream of PI 3-kinase that has been implicated in down regulation of insulin signalling [16, 28]. Our results show that insulin-induced phosphorylation of $\mathrm{Ser}^{307}$ requires the activation of mTOR. This pathway seems to 
be the major one used by insulin to induce the phosphorylation of $\mathrm{Ser}^{307}$ both in 3T3-L1 adipocytes and in vivo, as it is in response to hyperosmotic stress [12]. However, since this serine residue can be phosphorylated by different kinases, we cannot completely rule out that other kinases could be involved in the phosphorylation of the $\mathrm{Ser}^{307}$. Indeed, JNK is also involved in insulin-induced phosphorylation of $\mathrm{Ser}^{307}$ in 3T3-L1 adipocytes although its inhibition only partly reduced the insulin-induced phosphorylation of $\mathrm{Ser}^{307}$ [29]. This suggests that different kinases are able to phosphorylate this site in response to insulin. In agreement with this hypothesis, full phosphorylation of $\mathrm{Ser}^{307}$ in IRS-1 in response to TNF $\alpha$ required the activation of both JNK and IKK- $\beta$ [30].

We also found that mTOR pathway is implied in the phosphorylation of $\mathrm{Ser}^{612} / \mathrm{Ser}^{632}$ following prolonged insulin stimulation of 3T3-L1 adipocytes or in muscles and adipose tissue of insulin-treated mice. Although mTOR activates the p70 S6-kinases 1 and 2 [31], they are unlikely to be involved in the phosphorylation of $\mathrm{Ser}^{307}$, $\mathrm{Ser}^{612}$, $\mathrm{Ser}^{632}$ that are not in the RXRXXS consensus sequence phosphorylated by those kinases [32]. Although we cannot exclude the involvement of an unidentified mTOR-regulated kinase in these phosphorylations, some observations are in favour of a direct phosphorylation of these sites by mTOR. Indeed, in agreement with another study [21] we show that mTOR and IRS-1 are constitutively associated and mTOR catalyses the phosphorylation of a set of Ser/Thr-Pro sites, as it is the case for the three considered serine residues in IRS-1 [31]. Moreover, TNF $\alpha$ induces the phosphorylation of IRS-1 on Ser632 by a mTOR dependent pathway [21]. In addition to playing a role in the phosphorylation of these three sites, the mTOR pathway seems implicated in the overall serine phosphorylation of IRS-1 since rapamycin treatment completely prevented the shift in the molecular weight of IRS-1 following prolonged insulin treatment. Importantly, insulin-induced activation of the mTOR pathway and phosphorylation of the different serine residues seem to be part of a feedback mechanism used by insulin to terminate its action. Indeed, we found that inhibition of this pathway by rapamycin prevented the rapid deactivation of PI 3-kinase in muscle when insulin stimulation is maintained. In L6 cells, amino acids that activate mTOR dramatically accelerated the time-dependent deactivation of PI 3-kinase in response to insulin [33]. Finally in 3T3L1 adipocytes $[12,28]$ and in the hepatoma cell line [34], mTOR inhibition prevents the insulin-induced degradation of IRS-1 that seems to be linked to the phosphorylation of the $\mathrm{Ser}^{307}$ [34] and to be regulated by a balance between serine compared with tyrosine phosphorylation of IRS-1 [35].

We also found that the MAP kinase pathway was required for the phosphorylation of $\mathrm{Ser}^{612} / \mathrm{Ser}^{632}$ following short-term insulin stimulation. Thus, as previ- ously described for the $\mathrm{Ser}^{307}$, several kinases are also able to phosphorylate these two serine residues. A first possibility could be that different pools of IRS-1 are phosphorylated. One pool could be rapidly phosphorylated by a MAP kinase-dependent pathway and another one, later on, by a mTOR pathway. Another hypothesis could be that the two serine residues in IRS-1 would be rapidly phosphorylated by the MAP kinase pathway, then dephosphorylated and phosphorylated again following activation of mTOR. The Ser612 and Ser632 are located close to two tyrosine residues $\left(\mathrm{Tyr}^{608}{ }^{6}, \mathrm{Tyr}^{628}\right)$ which are major phosphorylation sites involved in the binding of the PI 3-kinase [22, $36]$ and are required for insulin-stimulated glucose uptake [22]. Several observations suggest that MAP kinase, by phosphorylating these sites, could negatively modulate the interaction between IRS-1 and the PI 3kinase. Indeed, mutation of these two serine residues enhances the PI 3-kinase activity associated with IRS1 [37] and prevents the inhibitory effect of PDGF on insulin-induced association of PI 3-kinase with IRS-1 [38]. Phosphorylation of $\mathrm{Ser}^{612}$ by the ERK in response to PMA inhibits insulin-induced IRS-1 tyrosine phosphorylation and its subsequent association with the PI 3-kinase [9, 10]. Moreover, we recently found that the basal phosphorylation of Ser636 in human IRS-1 (corresponding to Ser ${ }^{632}$ in the rat) was increased in primary cultures of myotubes from patients with Type 2 diabetes [39]. In parallel, the insulin-induced association of PI 3-kinase with IRS-1 was reduced in these cells and the basal activity of MAP kinase was increased [39]. However, we did not observe a modification of insulin-induced IRS-1 tyrosine phosphorylation or IRS-1-associated PI 3-kinase activity following inhibition of MAP kinase pathway by the MEK inhibitor PD98059 in 3T3-L1 adipocytes. Thus, more investigations are required to clarify the consequence of the phosphorylation of these two serine residues by MAP kinase after short-term insulin stimulation.

The complexity of the regulation of IRS-1 Ser/Thr phosphorylation in response to insulin suggests an important physiological role to accurately tune the insulin signalling. This process could be important for the specificity of insulin action. For instance, PIP3 signals have to be precisely regulated both in amplitude and duration to induce the insertion of GLUT4 into the plasma membrane [40]. This regulation could explain in part the specific effect of insulin on GLUT4 translocation, compared to other stimuli that activate PI 3-kinase but not GLUT4 translocation [40]. Phosphorylation of $\mathrm{Ser}^{612 / \mathrm{Ser}^{632}}$ in addition to the phosphorylation of the closely located tyrosine residues could regulate PI 3-kinase activation to produce PIP3 signals with a time course and an amplitude which allow for GLUT4 translocation. Phosphorylation of $\mathrm{Ser}^{307}$ could have a more general role to favour the dephosphorylation of all tyrosine phos- 
phorylation sites in IRS-1 and thus the end of insulin signalling. Several factors involved in insulin resistance could take advantage of this process to downregulate insulin action [16] and abnormal Ser/Thr phosphorylation of IRS-1 in obesity or Type 2 diabetes due to hyperinsulinaemia could also exacerbate the insulin resistance. We provide strong evidence that mTOR plays a key role in the phosphorylation of these sites following prolonged insulin stimulation. mTOR, which is an important mediator for cross-talk between nutritional signals and metabolic signals of insulin $[41,42]$ could play a central role in the regulation of insulin signalling in obesity and Type 2 diabetes where the amounts of amino acids and/or glucose are increased and thus could be a pharmacological target to reduce insulin resistance.

Acknowledgements. This work was supported by grants from the Institut National de la Santé et de la Recherche Médicale (France), the University of Nice, the Fondation BettencourtSchueller, the Fondation pour la Recherche Médicale, the Région Provence Alpes Côte d'Azur and the Conseil Général des Alpes Maritimes. This work was also supported by a grant from ALFEDIAM-Takeda Laboratories (Puteaux, France) to J.-F. Tanti. P. Gual was successively supported by a Fellowship from La Ligue Contre le Cancer and from ALFEDIAM. We thank Drs G. Thomas and M. Pende for helpful discussions and critical reading of the manuscript.

\section{References}

1. DeFronzo RA (1997) Pathogenesis of type 2 diabetes:metabolic and molecular implications for identifying diabetes genes. Diabet Rev 5:177-269

2. White MF (2002) IRS proteins and the common path to diabetes. Am J Physiol Endocrinol Metab 283:E413-422

3. Bell GI, Polonsky KS (2001) Diabetes mellitus and genetically programmed defects in beta-cell function. Nature 414:788-791

4. Saltiel AR, Kahn CR (2001) Insulin signalling and the regulation of glucose and lipid metabolism. Nature 414: 799-806

5. Giovannone B, Scaldaferri ML, Federici M, Porzio O, Lauro D, Fusco A, Sbraccia P, Borboni P, Lauro R, Sesti G (2000) Insulin receptor substrate (IRS) transduction system: distinct and overlapping signaling potential. Diabetes Metab Res Rev 16:434-441

6. Sesti G, Federici M, Hribal ML, Lauro D, Sbraccia P, Lauro R (2001) Defects of the insulin receptor substrate (IRS) system in human metabolic disorders. FASEB J 15:2099-2111

7. Carvalho E, Jansson PA, Axelsen M, Eriksson JW, Huang X, Groop L, Rondinone C, Sjostrom L, Smith U (1999) Low cellular IRS 1 gene and protein expression predict insulin resistance and NIDDM. FASEB J 13:2173-2178

8. Tanti JF, Grémeaux T, Van Obberghen E, Le MarchandBrustel Y (1994) Serine/threonine phosphorylation of insulin receptor substrate 1 modulates insulin receptor signaling. J Biol Chem 269:6051-6057

9. De Fea K, Roth RA (1997) Modulation of insulin receptor substrate1 tyrosine phosphorylation and function by mitogen-activated protein kinase. J Biol Chem 272:31400 31406
10. De Fea K, Roth RA (1997) Protein kinase C modulation of insulin receptor substrate-1 tyrosine phosphorylation requires serine 612. Biochemistry 36:12939-12947

11. Ricort JM, Tanti JF, Van Obberghen E, Le Marchand-Brustel Y (1997) Cross-talk between the platelet-derived growth factor and the insulin signaling pathways in 3T3-L1 adipocytes. J Biol Chem 272:19814-19818

12. Gual P, Gonzalez T, Grémeaux T, Barrès R, Le MarchandBrustel Y, Tanti JF (2003) Hyperosmotic stress inhibits IRS-1 function by distinct mechanisms in 3T3-L1 adipocytes. J Biol Chem 278:26550-26557

13. Shulman GI (2000) Cellular mechanisms of insulin resistance. J Clin Invest 106:171-176

14. Paz K, Liu YF, Shorer H, Hemi R, LeRoith D, Quan M, Kanety H, Seger R, Zick Y (1999) Phosphorylation of insulin receptor substrate-1 (IRS-1) by protein kinase B positively regulates IRS-1 function. J Biol Chem 274:2881628822

15. Greene MW, Garofalo RS (2002) Positive and negative regulatory role of insulin receptor substrate 1 and 2 (IRS-1 and IRS-2) serine/threonine phosphorylation. Biochemistry 41:7082-7091

16. Zick Y (2001) Insulin resistance: a phosphorylation-based uncoupling of insulin signaling. Trends Cell Biol 11:437441

17. Sykiotis GP, Papavassiliou AG (2001) Serine phosphorylation of insulin receptor substrate-1: a novel target for the reversal of insulin resistance. Mol Endocrinol 15:18641869

18. Yu C, Chen Y, Cline GW, Zhang D, Zong H, Wang Y, Bergeron R, Kim JK, Cushman SW, Cooney GJ, Atcheson B, White MF, Kraegen EW, Shulman GI (2002) Mechanism by which fatty acids inhibit insulin activation of IRS-1 associated phosphatidylinositol 3-kinase activity in muscle. J Biol Chem 277:50230-50236

19. Aguirre V, Uchida T, Yenush L, Davis R, White MF (2000) The c-Jun NH2-terminal kinase promotes insulin resistance during association with insulin receptor substrate-1 and phosphorylation of Ser307. J Biol Chem 275:9047-9054

20. Aguirre V, Werner ED, Giraud J, Lee YH, Shoelson SE, White MF (2002) Phosphorylation of Ser307 in insulin receptor substrate-1 blocks interactions with the insulin receptor and inhibits insulin action. J Biol Chem 277:15311537

21. Ozes ON, Akca H, Mayo LD, Gustin JA, Maehama T, Dixon JE, Donner DB (2001) A phosphatidylinositol 3-kinase/Akt/mTOR pathway mediates and PTEN antagonizes tumor necrosis factor inhibition of insulin signaling through insulin receptor substrate-1. Proc Natl Acad Sci USA 98:4640-4645

22. Esposito DL, Li Y, Cama A, Quon MJ (2001) Tyr(612) and $\operatorname{Tyr}(632)$ in human insulin receptor substrate-1 are important for full activation of insulin-stimulated phosphatidylinositol 3-kinase activity and translocation of GLUT4 in adipose cells. Endocrinology 142:2833-2840

23. Rui L, Aguirre V, Kim J, Shulman GI, Lee A, Corbould A, Dunaif A, White MF (2001) Insulin/IGF-1 and TNF-alpha stimulate phosphorylation of IRS-1 at inhibitory Ser307 via distinct pathways. J Clin Invest 107:181-189

24. Heydrick SJ, Jullien D, Gautier N, Tanti JF, Giorgetti S, Van Obberghen E, Le Marchand-Brustel Y (1993) Defect in skeletal muscle phosphatidylinositol-3-kinase in obese insulin-resistant mice. J Clin Invest 91:1358-1366

25. Jiang G, Dallas-Yang Q, Liu F, Moller DE, Zhang BB (2003) Salicylic acid reverses phorbol 12-myristate-13-acetate (PMA)- and tumor necrosis factor alpha (TNFalpha)induced insulin receptor substrate 1 (IRS1) serine 307 
phosphorylation and insulin resistance in human embryonic kidney 293 (HEK293) cells. J Biol Chem 278:180-186

26. Hirosumi J, Tuncman G, Chang L, Gorgun CZ, Uysal KT, Maeda K, Karin M, Hotamisligil GS (2002) A central role for JNK in obesity and insulin resistance. Nature 420: 333-336

27. Gao Z, Hwang D, Bataille F, Lefevre M, York D, Quon MJ, Ye J (2002) Serine phosphorylation of insulin receptor substrate 1 by inhibitor kappa B kinase complex. J Biol Chem 277:48115-48121

28. Takano A, Usui I, Haruta T, Kawahara J, Uno T, Iwata M, Kobayashi M (2001) Mammalian target of rapamycin pathway regulates insulin signaling via subcellular redistribution of insulin receptor substrate 1 and integrates nutritional signals and metabolic signals of insulin. Mol Cell Biol 21:5050-5062

29. Lee YH, Giraud J, Davis RJ, White MF (2003) c-Jun Nterminal kinase (JNK) mediates feedback inhibition of the insulin signaling cascade. J Biol Chem 278:2896-2902

30. Gao Z, Zuberi A, Quon M, Dong Z, Ye J (2003) Aspirin inhibits serine phosphorylation of IRS-1 in TNF-treated cells through targeting multiple serine kinases. J Biol Chem 278:24944-24950

31. Kozma SC, Thomas G (2002) Regulation of cell size in growth, development and human disease: PI3 K, PKB and S6 K. Bioessays 24:65-71

32. Flotow H, Thomas G (1992) Substrate recognition determinants of the mitogen-activated $70 \mathrm{~K}$ S6 kinase from rat liver. J Biol Chem 267:3074-3078

33. Tremblay F, Marette A (2001) Amino acid and insulin signaling via the mTOR/p70 S6 kinase pathway. J Biol Chem 276:38052-38060

34. Greene MW, Sakaue H, Wang L, Alessi DR, Roth RA (2003) Modulation of insulin stimulated degradation of human insulin receptor substrate- 1 by serine 312 phosphorylation. J Biol Chem 278:8199-8211
35. Pederson TM, Kramer DL, Rondinone CM (2001) Serine/ threonine phosphorylation of IRS-1 triggers its degradation: possible regulation by tyrosine phosphorylation. Diabetes 50:24-31

36. Rocchi S, Tartare-Deckert S, Mothe I, Van Obberghen E (1995) Identification by mutation of the tyrosine residues in the insulin receptor substrate-1 affecting association with the tyrosine phosphatase $2 \mathrm{C}$ and phosphatidylinositol 3-kinase. Endocrinology 136:5291-5297

37. Mothe I, Van Obberghen E (1996) Phosphorylation of insulin receptor substrate- 1 on multiple serine residues, 612, 632, 662, and 731, modulates insulin action. J Biol Chem 271:11222-11227

38. Li J, DeFea K, Roth RA (1999) Modulation of insulin receptor substrate-1 tyrosine phosphorylation by an Akt/ phosphatidylinositol 3-kinase pathway. J Biol Chem 274: 9351-9356

39. Bouzakri K, Roques M, Gual P, Espinosa S, GuebreEgziabher F, Riou J-P, Laville M, Le Marchand-Brustel Y, Tanti JF, Vidal H (2003) Reduced activation of phosphatidylinositol-3 kinase and increased serine 636 phosphorylation of insulin receptor substrate- 1 in primary culture of skeletal muscle cells from patients with type 2 diabetes. Diabetes: 52:1319-1325

40. Tengholm A, Meyer T (2002) A PI3-kinase signaling code for insulin-triggered insertion of glucose transporters into the plasma membrane. Curr Biol 12:1871-1876

41. Dennis PB, Fumagalli S, Thomas G (1999) Target of rapamycin (TOR): balancing the opposing forces of protein synthesis and degradation. Curr Opin Genet Dev 9:49-54

42. Shah OJ, Anthony JC, Kimball SR, Jefferson LS (2000) 4E-BP1 and S6K1: translational integration sites for nutritional and hormonal information in muscle. Am J Physiol Endocrinol Metab 279:E715-E729 